\title{
Synergistic effects of Persicaria odorata (Daun Kesom) leaf extracts with standard antibiotics on pathogenic bacteria
}

\author{
P. M. Ridzuan ${ }^{\text {a* }}$, Hairul Aini Hamzah ${ }^{\mathrm{a}}$, Anis Shah ${ }^{\mathrm{b}}$, Norazian Mohd Hassan ${ }^{\mathrm{c}}$, Baharudin Roesnita ${ }^{\mathrm{d}}$ \\ ${ }^{a}$ Department of Basic Medical Sciences, Kulliyyah of Medicine, International Islamic University, \\ Malaysia (IIUM), 25200 Kuantan Pahang, Malaysia. \\ ${ }^{b}$ Department of Internal Medicine, Kulliyyah of Medicine, International Islamic University, \\ Malaysia (IIUM), 25200 Kuantan Pahang, Malaysia. \\ 'Department of Pharmaceutical Chemistry, Kulliyyah of Pharmacy, International Islamic University, \\ Malaysia (IIUM), 25200 Kuantan Pahang, Malaysia. \\ ${ }^{d}$ Department of Pathology, Hospital Tengku Ampuan Afzan, 25200 Kuantan Pahang, Malaysia.
}

\begin{abstract}
Antibacterial activity of different types of $P$. odorata leaf extracts was evaluated in combination with standard antibiotics. Persicaria. odorata leaves were extracted with $n$-hexane ( $n$-hex), dichloromethane $(\mathrm{DCM})$ and methanol $(\mathrm{MeOH})$. Each extract was applied on vancomycin $(30 \mu \mathrm{g})$, erythromycin $(15 \mu \mathrm{g})$ and gentamicin $(10 \mu \mathrm{g})$ discs, respectively. Disk diffusion method was used to evaluate the synergistic activity of each combination on Staphylococcus aureus, Staphylococcus epidermidis, Streptococcus pyogenes, Streptococcus pneumoniae, Pseudomonas aeruginosa, Salmonella typhi, and Escherichia coli. Minimum inhibitory concentration (MIC) and gas chromatography mass spectrometry (GCMS) analysis was performed on the active extract. Synergistic effects seen were mainly from the $n$-hex+antibiotics combinations, mainly on the Gram-positive bacteria (7 additive, 5 antagonistic), with MIC range from $50 \mu \mathrm{g} / \mathrm{ml}$ to $100 \mu \mathrm{g} / \mathrm{ml}$, as well as Gram-negative bacteria ( 2 additive, 2 indifferent, 5 antagonistic). In particular, synergism showed by the combination of $n$-hex+van were all additive against the susceptible bacteria. DCM extract combination showed synergistic effects on three Gram-positive species (S. aureus, S. epidermidis, S. pyogenes). Meanwhile, $\mathrm{MeOH}+$ antibiotics combination showed significant additive synergistic effects $(p<0.05)$ on $S$. aureus and S. epidermidis. The major compounds of leaves extract were decanal and B-citral. $n$-Hex extract superiorly inhibited Gram-positive bacteria growth as compared to DCM and $\mathrm{MeOH}$ extracts. The additive synergistic property of the $n$-hex $P$. odorata extract could be further studied for possible use as an antibacterial agent.
\end{abstract}

Keywords: Persicaria odorata leaf extracts, synergy antimicrobial activity, antibiotics.

\section{Introduction}

In recent years, the occurrences of antibiotic resistance in the clinical setting are increasing due to prolonged use and misuse of antimicrobial drugs. Some of the pathogens are resistant to multiple drugs. ${ }^{1}$ Current alarm in clinical bacteriology is the existence of extended-spectrum B-lactamase producing bacteria that causes serious manifestation including high rate of mortality as the choice for effective antibiotics are limited. Because of that, the search for new antimicrobial substances is very important and investigation on the biological

Corresponding author:

Dr. P.M. Ridzuan

Deparment of Basic Medical Sciences

Kulliyyah of Medicine

International Islamic University Malaysia

Kuantan, Pahang, Malaysia

Tel: 013-4748695

E-mail: ridzuan_pauzi@yahoo.com properties of medicinal plants might provide a new insight on the natural antimicrobial agents as part of treatment regime. The use of herbs for medicinal purposes has long been practiced since the history of mankind and nowadays it has been acceptable in many parts of the world, particularly in the past 20 years. ${ }^{2}$ The Malaysian government has established the Traditional and Complementary Medicine Division under the Ministry of Health since 1987 with the vision to integrate traditional medicine optimally into the National health system. Furthermore, assessment on synergistic effects between medicinal plants and standard antibiotics has been extensively investigated in phytomedicine research since many infection produce complex signs and symptoms could be addressed with their combinations. ${ }^{3,4,5}$ Interaction of drugs or synergy can be classified as additive, indifference and antagonism. A combination which is not effective or does not inhibit selected microbes is called drug antagonism due to drug-to-drug interaction between the active compounds of the extract and antibiotic, which produce less antibiotic sensitivity of selected microorganisms. 
Persicaria odorata is one of the natural plants that have been traditionally used in Southeast Asian cuisine. It is classified under family of Polygonaceae and genus of Persicaria. ${ }^{6}$ This plant grows in tropical and subtropical zones in warm and damp area. In stable condition, they can grow up to 15 to $30 \mathrm{~cm}{ }^{7}$ It belongs to a group of fresh culinary herbs which are known as the cilantro mimics with the 'cilantro' flavor. The leaves are usually used for flavor in culinary and also used as additional flavor to curries and hot soups. It has many names which include Vietnamese cilantro, Vietnamese mint and Vietnamese coriander. In Vietnam it is called as "rau ram", while in Malaysia, Brunei and Singapore it is known as "daun kesom" or "daun laksa".

Previous studies have shown that $P$. odorata has wide variety of pharmacological effects and some of them are tremendously beneficial such as antioxidant $^{9}$, antibacterial ${ }^{10,11}$ anti-inflammatory ${ }^{12}$ and anticancer ${ }^{13,14}$. Therefore, the use of the plant in food is a good practice since it could possibly maintain or enhance bodily functions and reduce the risk of diseases. The interaction of the plant extract with conventional antibiotics is yet to be identified. Thus, in this study, the antibacterial effect of various types of $P$. odorata leaf extracts on common pathogenic bacteria was recorded and interactions of the leaf extracts with standard antibiotics were further investigated by disc diffusion method.

\section{Methods}

\section{Plant material and extraction}

Persicaria odorata plants were obtained from Taman Pertanian Jubli Perak, Indera Mahkota, Kuantan, Pahang, Malaysia. The plant was identified by botanist, Asst. Prof. Dr. Norazian Binti Mohd Hassan from Natural Medicinal Products Centre, Kuliyyah of Pharmacy, IIUM (voucher specimen: PIIUM 0264). The plant leaves were separated, cleaned and dried before grinding into powder. Extraction process was performed consecutively in $n$-hexane ( $n$-hex; non-polar solvent), dichloromethane (DCM; semi-polar solvent) and methanol (MeOH; polar solvent). Initially, the powder was soaked in $n$-hex for 24 hours at ambient temperature with continuous shaking at $200 \mathrm{rpm}$. Then the suspension was filtered through Whatman filter $(6 \mathrm{~mm}$ in diameter), leaving a residue on the filter paper. The filtrate (extract), was then concentrated in a vacuum at 40 ${ }^{\circ} \mathrm{C}$ using rotary evaporator (Buchi, Switzerland) for $2 \mathrm{~h}$. The residue, which was placed on the filter paper, underwent a drying process in a fume hood for one day. The dried residue was then mixed with DCM for the semi-polar compounds extraction. Finally, the residue was treated in a similar way as the previous by using $\mathrm{MeOH}$ to obtain the polar compounds extract. The extracts were kept in a refrigerator at $4^{\circ} \mathrm{C}$ until use. The yields for $n$-hex, $\mathrm{DCM}$ and $\mathrm{MeOH}$ extracts were $0.96 \%, 1.35 \%$ and $7.984 \%$ respectively.
Microorganisms and standard antibiotics used

The American Type Culture Collection (ATCC) strains of Staphylococcus aureus (ATCC 25923), Staphylococcus epidermidis (ATCC 12228), Streptococcus pneumoniae (ATCC 49619), and Streptococcus pyogenes (ATCC 19615), Pseudomonas aeruginosa (ATCC 27853), Salmonella typhi (ATCC 14028) and Escherichia coli (ATCC 25922) were used in this experiment. Mueller-Hinton agar (MHA) and blood agar (BA) were used for culture and antimicrobial screening test purposes. Antibiotics discs vancomycin (van; $30 \mu \mathrm{g}$ ), erythromycin (ery; $15 \mu \mathrm{g}$ ), and gentamycin (gent;10 $\mu \mathrm{g}$ ) were used for the study (Oxoid Ltd England). Each antibiotic used represented certain class of antibiotic which were B-lactam glycopeptides, macrolides, and aminoglycoside, respectively.

\section{Discs preparation}

Discs were made from Whatman filter paper no.3. since it can absorb all types of extracts and are not easily damaged once they were applied on the agar plates. The filter papers were punched using a paper puncher to produce $6 \mathrm{~mm}$ diameter disk (similar diameter with antibiotic disc). After that, the discs were sterilized by autoclaving and stored in a refrigerator until use.

\section{Combination disks preparation and antibacterial screening}

Two hundred microlitres $(200 \mu \mathrm{l})$ of $400 \mu \mathrm{g} / \mathrm{ml}$ of each of the extract was applied on the respective antibiotic discs by pipetting and then allowed to dry. Using disc diffusion method, the antibacterial screening was performed by placing the prepared discs on the culture plate at an equidistant position. The plates were incubated at $37^{\circ} \mathrm{C}$ for 24 hours. The inhibition zone of the inoculum was determined by measuring the diameter $(\mathrm{mm})$ of zone of inhibition. As for control, screenings using discs with antibiotic only and the extract only were also done in parallel. Synergistic effects were identified as additive, indifferent or antagonist, which was demonstrated by comparing the inhibition zones of the extract combination to the antibiotic-only controls. Triplicates were done for each test and the data were analyzed statistically using one-way ANOVA, and $\mathrm{p}<0.05$ was considered significant with $95 \%$ confidence interval.

\section{Minimum Inhibitory Concentration}

The broth microdilution assay was performed in sterile 96 -well round bottom microtitre plates. A two-fold dilution of the test extract was prepared by mixing with Dimethy sulfoxide (DMSO), that gave a range of 100 to $0.049 \mu \mathrm{g} / \mathrm{ml}$ of concentration. Twenty microlitres $(20 \mu \mathrm{l})$ of each concentration of extract was pipetted into each well of the microtitre plates. After that, $180 \mu \mathrm{l}$ of each of the growing selected bacterial isolates at $1 \times 10^{4} \mathrm{CFU} / \mathrm{ml}$ to $1 \times 10^{5} \mathrm{CFU} / \mathrm{ml}$ was put into each well. In parallel, erythromycin as the positive control was used. Sterile broth was tested for the sterility control. After $24 \mathrm{~h}$ incubation period at $37^{\circ} \mathrm{C}$, 
a drop of $0.25 \%$ 3-[4,5-dimethylthiazol-2-yl]-2,5diphenyl-tetrazolium bromide or MTT (SIGMA, M2128) was added into each well and the plate was incubated at $37^{\circ} \mathrm{C}$ for $30 \mathrm{~min}$. The color change from yellow to purple indicates that active metabolism occurred during the microbe's growth

Phytochemical profiling of the most active extract Phytochemical profiling of the $P$. odorata extract was determined by Gas Chromatography Mass Spectrometer (GCMS) Agilent 6890 series (Agilent GC system, US). An aliquot of $1 \mu \mathrm{l}$ of $n$-hex extract was applied on the GCMS which was fitted with $30 \mathrm{~m}$ $x 0.25 \mathrm{~mm} \times 0.25 \mathrm{um}$ film thickness, HP5-ms capillary. The carrier gas was helium at flow rate $0.57 \mathrm{ml} / \mathrm{min}$ using splitless method.

\section{Result}

Antibacterial activity of the extract alone on pathogenic bacteria

The $n$-Hex extract inhibited the growth of the Gram -positive cocci tested but not the Gram-negative bacteria (Table 1). Inhibition of growth was also seen on the DCM extract against three cocci ( $S$. aureus, S. epidermidis and S. pyogenes) and $\mathrm{MeOH}$ extract against two cocci (S. aureus, $S$ epidermidis). Only one species of Gram-negative bacteria (S. typhi) was affected by DCM extract. As for the $n$-hex extract, the MIC value is $100 \mu \mathrm{g} / \mathrm{ml}$ for S. aureus and $50 \mu \mathrm{g} / \mathrm{ml}$ for S. epidermidis, S. pneumoniae and S. pyogenes.

Table 1: Synergistic effects of three different $P$. odorata extracts in combination with standard antibiotics against selected bacteria indicated by the zone of inhibition. The values are means \pm standard deviation. The effects were evaluated by comparing the values of the combination substrate to the values of the antibiotic-only control.

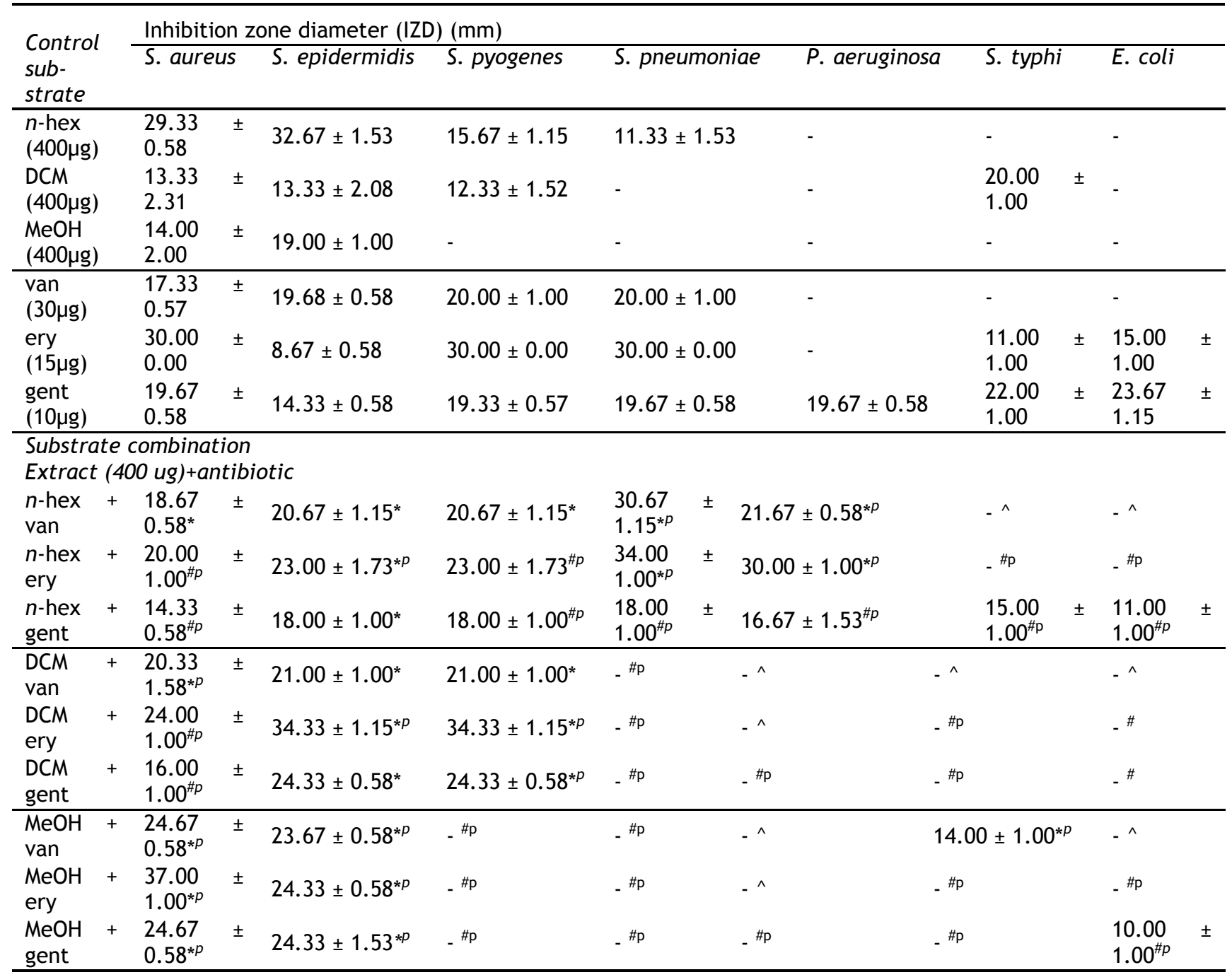

${ }^{*}=$ additive effect, $\#$ = antagonistic effect, ${ }^{\wedge}=$ indifferent effect,$-=$ no inhibition, ${ }^{P}=$ significantly different $(p<0.05)$, $\mathrm{n}$-hex = $\mathrm{n}$ - hexane, $\mathrm{DCM}=$ dichloromethane, $\mathrm{MeOH}=$ methanol, van = vancomycin, ery = erythromycin, gent = gentamycin 


\section{Synergistic effect of extract combination with} antibiotics on the Gram-positive cocci

Bacterial growth that were inhibited by the extracts alone was also inhibited by the extract in combination with the antibiotics and similar findings were obtained for the non-susceptible ones (Table $1)$. Generally, the combination of $P$. odorata leaf extracts with the antibiotics-only control showed synergistic effect on the Gram-positive cocci. Out of the thirty six (36) Gram positive cocci inoculums, twenty $(55.6 \%)$ were additive, none was indifferent (0\%) and sixteen (44.4\%) were antagonistic. Among the nine extracts combinations, $n$-hex+van was additive on all the cocci tested especially on $S$. pneumoniae $(p<0.05)$. S. pneumoniae was also significantly inhibited by $n$-hex+ery, however it was not inhibited by other type of extract combinations. Cocci that were inhibited by all type of extracts were S. aureus and S. epidermidis. Significant additive synergistic effect was seen on DCM+van and the entire $\mathrm{MeOH}$ extract combinations.

Extract combinations of $\mathrm{MeOH}$ showed no antibacterial activity against $S$. pneumoniae and $S$. pyogenes and similar findings was obtained for the DCM extract combinations against S. pneumoniae. In contrast, the use of antibiotics alone did inhibit the growth of the bacteria significantly, thus indicated antagonistic effect of the extract on the action of the antibiotics on S. pneumoniae and S. pyogenes.

\section{Synergistic effect of extract combination with antibiotics on the Gram-negative rods}

Interestingly, the $n$-hex+van and $n$-hex+ery also significantly inhibited $P$. aeruginosa growth on the agar medium, which was not observed from the plates of antibiotic alone, which indicated significant additive effect. Another significant additive effect was seen on $\mathrm{MeOH}+$ van against $\mathrm{S}$. typhi. Majority of the plates of the Gram negative rods showed no activity ( 20 out of 27 plates), which some of them are antagonist (15/20).

\section{Phytochemical profiling}

The result of phytochemical analysis of the $n$-hex leaf extract is shown in Table 2 . Twenty eight major peaks of volatile compounds were revealed by the GSMS analysis. The major volatile compounds were identified as decanal, B-citral, a-citral, dodecanal, caryophyllene, euparone, drimenol and alkene.

Table 2: Eight major compounds of $P$. odorata leaves extract

\begin{tabular}{lcl}
\hline Compound & Composition (\%) & $\begin{array}{l}\text { Chemical } \\
\text { classification }\end{array}$ \\
\hline Decanal & 27.11 & Aldehyde \\
B-citral & 4.11 & Aldehyde \\
a-citral & 2.53 & Aldehyde \\
Dodecanal & 1.73 & Aldehyde \\
Caryophyllene & 1.71 & Alkene \\
Euparone & 1.25 & Benzofurane \\
Drimenol & 1.03 & Alcohol \\
2,4-heptadiene,2,6- & 1.0 & Alkene \\
dimethyl & & \\
\hline
\end{tabular}

\section{Discussion}

Searching for new potential of antibacterial substances from easily accessible and cheap sources such as herbs is important for alternative treatment regime. Beneficial phytochemical compounds that are abundant in aromatic plants such as $P$. odorata can be explored by different techniques of extraction. Method of extraction may influence the chemical and volatile properties. ${ }^{14}$ Therefore, we have carried out this study using P.odorata leaves, in which the leaf extracts were prepared with three different solvents.

In our study, $n$-hex extract generally showed the most potent antibacterial effect as compared to the other two extracts even though the yield for $n$-hex showed the lowest $(0.96 \%)$. The extract alone inhibited the entire Gram positive cocci tested and this was not shown by the other $P$. odorata leaf extracts. The activity of the $n$-hex extract alone on the cocci was similar to the vancomycin antibiotics even though the MIC for the extract was much higher as compared to the antibiotic. Previous study carried out by Nanasombat \& Teckchuen ${ }^{13}$, has documented that $P$. odorata (also known as Polygonum odoratum) contained strong antibacterial activity among 20 species of the Thai local vegetables. They also reported the flavonoids found in the plant. In the study, only methanol extraction was employed which possessed antibacterial activity against Bacillus cereus, E.coli, Listeria monocytogene, P. fluorescens, S. aureus and Yersinia enterocolitica. Similar research approach that included also several methods of extraction on involving two bacterial species, Bacillus subtilis and E. coli, was done by Jamal et al. ${ }^{15}$. Antibacterial effect of methanol and ethanol extracts of $P$. odorata against $B$. subtilis was observed in the study. The potential of the phytochemicals of the plant as antibacterial has also been explored by Sasongko et al. ${ }^{11}$. Essential oil from the plant was extracted using hydrodistillation and evaluated on S. aureus and E.coli. The growth of both bacteria was inhibited by the essential oil. Yet, synergistic evaluation of their extracts with other compounds has yet to be done.

The major compound of the $n$-hex extract was decanal that could be the active substance against the bacteria. Isolation and biological activity investigation of decanal has indicated that it has potent antibacterial property. ${ }^{16}$ Decanal is a compound of aldehyde along with dodecanal. These compounds are also found in the study carried out by Sasongko et al. ${ }^{11}$, which was detected in both fresh $(7.32 \%)$ and dried $(4.47 \%)$ leaves. Other classes of volatile compound found in the leaf extract was terpene, which has a wide range of pharmacological values. $^{17,18}$

Interaction of herb extracts with other chemical substances is worth to be investigated to determine their synergistic effect. Factors that are relevant to 
the synergism include the nature of the test organisms, the size of inoculums, the culture media and the incubation temperature. All of the factors were controlled in the present study, including the concentration of the extracts plus the antibiotic and the controls with either the extract-only or antibiotic-only treatments. Triplicates of each plates were also carried out to exclude any outliers and for statistical analysis. The assessment of the extract in combination with the antibiotics was done using disc diffusion method. This method was a simplified method for qualitative comparison between the extract combination and the antibiotic alone.

To date, this is the first report on the synergism effects of $P$. odorata extracts with antibiotics. The combinations of $n$-hex extract with the three antibiotics gave a broad range of susceptibility, wherein $n$-hex+gent combination gave the broadest range of susceptibility results for all the bacterial isolates, as expected, even though mixed results of synergism were observed. However, none of the isolates were significantly inhibited by the $n$ hex+gent suggested reduce effectiveness of gentamycin with the $n$-hex $P$. odarata leaves extract. In contrast, the antibacterial activity of vancomycin was enhanced by the $n$-hex extract on the Gram positive cocci tested as well as an isolate of the Gram negative ( $P$. aeruginosa). Vancomycin is a glycopeptide antibiotic that affects peptidoglycan synthesis of the cocci by preventing the cross-linking of amino acids. How the $n$-hex extract may enhance its activity requires further investigation to understand the role of $n$-hex extract in vancomycin antibacterial activity or vice-versa. It is worth to highlight the susceptibility of $P$. aeruginosa with the extract combination as vancomycin alone did not inhibit the bacteria growth. Similar finding was recorded for erythromycin where combination of $n$ hex+ery significantly inhibited the growth of $P$. aeruginosa. Further study on the interaction of the combination against the bacteria would give clear understanding on the interaction mechanism.

The $\mathrm{MeOH}$ extract alone was active against $S$. aureus and $\mathrm{S}$. epidermidis and similar finding was recorded in the combination of $\mathrm{MeOH}+$ antibiotics with significant additive effects $(p<0.05)$. This evidence may justify the basis of traditional practice of certain Malaysian population who utilized $P$. odorata leaves to treat certain skin infections. However, other bacteria were not sensitive to $\mathrm{MeOH}$ extract alone. Study done by Nanosombat \& Teckchuen indicated that $E$. coli can be inhibited by $\mathrm{MeOH}$ extract of $P$. odorata but not in this study. ${ }^{13}$ This was perhaps due to different method of leaves extract preparation, in which the leaves were freeze dried before ground into powder. This method would actually preserved perishable compounds composition as it was prepared from the fresh leaves. Therefore, the composition of active compound such as decanal was higher in their extract. S. typhi was also significantly inhibited by the $\mathrm{MeOH}+\mathrm{van}$ combination.

\section{Conclusion}

In conclusion, different types of $P$. odorata leaf extracts possessed different antibacterial activity against Gram positive cocci. The antibacterial activity of the substrate combinations was concordance with the activity in the extract alone for the Gram positive cocci. There were synergistic effects in the combination of the extracts with antibiotics. Thus, the extracts need to be investigated further for possible use in formulation of antimicrobial compounds.

\section{References}

1. Cantas L, Syed QA, Shah LM, Cavaco CM, Manaia F, Walsh M, Popowska H, Garelick H, Bürgmann H, Sørum (2013). A brief multidisciplinary review on antimicrobial resistance in medicine and its linkage to the global environmental microbiota. Front Microbiol, 4: (96):1-14.

2. WHO (2011). Legal status of traditional medicine and complementary/alternative medicine : A worldwide review.[http:// apps.who.int/medicinedocs/pdf/h2943e/ h2943e.pdf].

3. Fankam AG, Kuete V, Voukeng IK, Kuiate JR, Pages JM (2011). Antibacterial activities of selected Cameroonian spices and their synergistic effects with antibiotics against multidrug-resistant phenotypes. BMC Complement Altern Med. (11):104.

4. Fred B (1996). Kesom Oil - a New Essential Oil. Int. Flavour and Fragrance Industry in First Aust. New Crops Conference. 2: 6.

5. Hassan WW (2007). Healing Herbs of Malaysia; Federal Land Development Authority (FELDA): Kuala Lumpur, Malaysia.

6. Carol SR (2008). Jump up Heavenly Fragrance: Cooking with Aromatic Asian Herbs, Fruits, Spices and Seasonings. Tuttle Publishing. p.29.

7. Qader SW, Abdulla MA, Chua LS, Hamdan S (2012). Potential Bioactive Property of Polygonum minus Huds (kesum) Review. Sci. Res. Essays. 7(2): 90-93.

8. Lee TK, Vairappan CS (2011). Antioxidant, Antibacteria and Cytotoxic Activities of Essential Oils and Ethanol Extracts of Selected South East Asian Herbs. J. Med Plants Res. 5 (21): 5284-5290.

9. Sasongko P, Laohankunjit N, Kerdchoechuen 0 (2011). Antibacterial activity of the essential oil from Persicaria odorata leaves. Agricultural Sci. J. 42(2): 105-108.

10. Wasman SQ, Mahmood AA, Salehhuddin H, Zahra AA, Salmah I (2010). Cytoprotective activities of Polygonum Minus aquoues leaf extract on ethanol-induced gastric ulcer in rats. J. Med. Plants Res. 4(24): 2658-2665.13) 
Nanasombat S, Teckchuen N (2009).

Antimicrobial, antioxidant and anticancer activities of Thai local vegetables. J Med Plants Res. 3(5): 443-449.

11. Mohamed MR, Vastano BC (2006). Identification of a structure specific $\mathrm{Bcl}-2$ phosphorylating homoisoflavone molecule from Vietnamese coriander (polygonatum odoratum) that induces apoptosis and G2/M cell cycle arrest in breast cancer cell lines. Food Chem. J. 104 (1): 332340.

12. Jamal $P$, Karim Al, Abdullah E, Raus RA, Hashim YZ (2011). Phytochemical Screening for Antibacterial Activity of Potential Malaysian Medicinal Plants. Afr. J. Biotechnol. 10(81): 18795-18799.

13. Liu K, Chen Q, Liu Y, Zhou X, Wang X (2012). Isolation and biological activities of decanal, linalool, valencene, and octanal from sweet orange oil. J. Food Sci. 77(11):C1156-61.

14. Degenhardt J, Kollner TG, Gershenzon J (2009). Monoterpene and sesquiterpene synthases and the origin of terpene skeletal diversity in plants. Phytochemistry J. 70: 1621-1637.

15. Bohlmann J, Keeling IC (2008). Terpenoid biomaterials. The Plant J. 54: 656-669. 